wWw.volsu.ru

DOI: https://doi.org/10.15688/nsr.jvolsu.2018.3.8

UDC 556.5(470.45)

LBC 26.222(2P-4Вог)

\title{
METHODOLOGICAL FOUNDATION OF GROUND-WATER DYNAMIC MODELING IN RIVER FLOODPLAINS ON THE EXAMPLE OF THE VOLGA-AKHTUBA FLOODPLAIN ${ }^{1}$
}

\author{
Denis A. Solodovnikov \\ Volgograd State University, Volgograd, Russian Federation
}

\begin{abstract}
The necessity for an integrated geographical approach to the study and modeling of ground-water dynamics in river floodplains is substantiated in the article. A preliminary and simplified classification of the types of annual ground and surface water level dynamics is proposed, which can serve as a basis for the differentiation of intrazonal floodplain landscapes. Thus differentiation is a scientific problem. In landscapes characterizing of the floodplains a descriptive approach prevails, and there are no quantitative criteria for differentiating such natural complexes. The research aims to study the interaction of the most important components of the landscape of a river floodplain - surface and groundwater, soil and vegetation. The research methodical feature is to obtain the accurate quantitative characteristics that can be formalized, processed by modern computers and comparable with data from other regions. This will be achieved by modern electronic equipment usage (georadar, spectroradiometer) and the development of digital models of the landscape components dynamics.

As a result of the research, objective, comparable with each other and in long-term dynamics, characteristics of floodplain landscapes will be obtained. The scientific significance of the work is to identify the links of surface and groundwater, soil and vegetation in the rivers floodplains of the arid zone, to obtain an objective quantitative basis for assessing changes in floodplain landscapes. Using the results of the research will allow us to subsequently evaluate the long-term changes in the components of the floodplain landscapes. The applied significance of the research is the ability to use the obtained model to predict the groundwater dynamics, and, accordingly, the forestgrowing conditions of the Volga-Akhtuba floodplain, the state of surface watercourse and underground water sources in rural areas.
\end{abstract}

Key words: floodplain, arid zone, Volga river, Volga-Akhtuba floodplain, groundwater, landscape, vegetation, soils.

УДК 556.5(470.45)

ББК 26.222(2Р-4Вог)

\section{МЕТОДОЛОГИЧЕСКИЕ ОСНОВЫ МОДЕЛИРОВАНИЯ ДИНАМИКИ ГРУНТОВЫХ ВОД РЕЧНЫХ ПОЙМ НА ПРИМЕРЕ ВОЛГО-АХТУБИНСКОЙ ПОЙМЫ ${ }^{1}$}

\author{
Денис Анатольевич Солодовников \\ Волгоградский государственный университет, г. Волгоград, Российская Федерация
}


ность на получение точных количественных характеристик, которые могут быть формализованы, обработаны современными компьютерами и сравнимы с данными по другим регионам. Этого позволит добиться использование современного электронного оборудования (георадар, спектрорадиометр) и разработка цифровых моделей динамики компонентов ландшафта.

В результате исследования будут получены объективные, сравнимые между собой и в многолетней динамике, характеристики пойменных ландшафтов. Научная значимость работы заключается в выявлении связей поверхностных и подземных вод, почв и растительности пойм рек аридной зоны, получении объективной количественной основы для оценки изменений пойменных ландшафтов. Использование результатов исследования позволит в последующем оценивать долговременные изменения компонентов пойменных ландшафтов. Прикладная значимость проекта заключается в возможности использовать полученную модель для прогнозирования динамики грунтовых вод, а соответственно и лесорастительных условий Волго-Ахтубинской поймы, состояния поверхностных водоемов и подземных источников водоснабжения в сельской местности.

Ключевые слова: речная пойма, аридная зона, Волга, Волго-Ахтубинская пойма, грунтовые воды, ландшафты, растительность, почвы.

Поймы рек являются важнейшим элементом экосистем более крупного ранга, местом концентрации животных и растений. Кроме того, поймы крупных рек обычно в значительной степени освоены в сельскохозяйственном отношении. Однако в исследовании ландшафтов пойм до сих пор преобладает описательный метод, получаемые результаты разнородны и с трудом сопоставимы между собой. Все это предопределяет актуальность исследований, направленных на получение точных количественных характеристик, которые могут быть формализованы, обработаны современными компьютерами и сравнимы с данными по другим регионам.

Влияние поверхностного и подземного стока на ландшафты пойм изучается уже не одно десятилетие. Наиболее изучена в этом отношении Волго-Ахтубинская пойма и дельта Волги - обширные и хорошо освоенные территории, в значительной степени выведенные из затопления. Влияние каскада гидроузлов на режим уровней и геоморфологические процессы в нижнем бьефе Волгоградской ГЭС изложено во множестве работ - от классической монографии И.В. Попова [12] до более свежих обобщающих публикаций $[2,16]$. Прикладные аспекты режима грунтовых вод (строительство мелиоративных систем, орошаемое овощеводство, рекреационное хозяйство) также освещены в литературе $[1,13,14$, 16]. Для участков северной части Волго-Ахтубинской поймы изучены также особенности восстановления гидрогеологического режима и ландшафтов при оптимизации режима поверхностных вод [17]. Общим местом ис- следований поймы Нижней Волги является констатация прогрессирующего засоления почв, остепнения лугов и усыхания лесов вследствие уменьшения общего объема половодья и изменений внутригодового распределения стока $[6,7,10,21]$. В целом, Нижнюю Волгу можно считать довольно популярным объектом исследования. В тоже время тренды развития пойменных ландшафтов Среднего Дона, развивающиеся в близких климатических условиях, совершенно не изучены. Они развиваются в условиях естественного гидрологического режима, однако здесь нами отмечены сходные признаки деградационных изменений ландшафтов [3].

Хорошо изучены общие вопросы гидрогеологии речных пойм $[11,23,24]$. Большое внимание в последние десятилетия уделяется экологическим аспектам проблемы [19, 22, 25, 26].

Общепринятым считается влияние зональных условий на особенности интразональных природных комплексов и компонентов [9]. Хорошо разработано классическое трехчленное деление пойм по высотным уровням (высокая, средняя и низкая пойма), которое определяет условия затопления в половодье, а также деление пойм на прирусловую, центральную полого-гривистую и притеррасную поймы [15].

Что же касается ландшафтной дифференциации самих интразональных природных комплексов, то здесь абсолютно преобладают частные исследования, носящие описательный характер $[4,5,7,20]$.

Необходимость выявления критериев типизации интразональных ландшафтов как протяженных природных объектов, широтной и дол- 
Д.А. Солодовников. Методологические основы моделирования динамики грунтовых вод речных пойм

готной дифференциации, разработки типологии ландшафтов речных пойм как фундаментальная научная проблема пока не ставилась.

Сами по себе интразональные ландшафты разных регионов изучены очень хорошо. Однако нигде в литературе мы не найдем четких количественных градаций и критериев интразональности. В сущности, географический феномен интразональности описан в литературе очень поверхностно, самыми общими фразами. Какая бы то ни было типология ландшафтов пойм, основанная на объективных количественных критериях, отсутствует. Между тем, поймы крупных рек имеют протяженность тысячи километров, и, безусловно, должны каким-то образом дифференцироваться. Детализировать представление об интразональности предполагается на примере самых типичных интразональных комплексов - речных пойм.

Нельзя путать этот подход с дифференциацией природных комплексов отдельных участков поймы в зависимости от продолжительности затопления (выделение уровней высокой, средней и низкой поймы и т. д.). Такой подход в литературе очень традиционен, но он дает возможность лишь сравнить отдельные участки поймы вдоль одного поперечного створа речной долины.

Наблюдения за режимом грунтовых вод южной части русской равнины, проведенные авторами в течение последних лет, показывают, что очень схематично можно выделить 3 типа динамики грунтовых вод речных пойм в меженный период (рис. 1):

1. Уровень грунтовых вод (УГВ) располагается выше уровня поверхностных водо- емов, зеркало грунтовых вод имеет уклон в сторону водоемов, которые в течение всего года дренируют пойму.

2. УГВ располагается субгоризонтально, соответствует уровню поверхностных водоемов.

3. УГВ располагается ниже уровня поверхностных вод, грунтовые воды в межень подпитываются из поверхностных водоемов. Образуются характерные для аридной зоны «висячие» озера и протоки.

На наш взгляд, тип динамики грунтовых вод является важнейшим фактором формирования пойменных ландшафтов. Именно этот фактор определяет лесопригодность пойм, видовой состав и состояние лесов. В самых общих чертах первый тип динамики связан с гумидными условиями (в поддержании УГВ большую роль играют атмосферные осадки теплого сезона), а третий с аридными. Второй тип можно считать переходным.

В каждом конкретном случае динамику грунтовых вод на любом створе речной поймы можно описать схемой (рис. 2). Очевидно, что в течение года имеется некоторое наиболее низкое положение этого уровня, и напротив, максимум, связанный с пиком весеннего половодья. Графически динамика грунтовых вод отражается как изменение площади заштрихованной фигуры на рисунке 2. По аналогии с изменением объемов водохранилищ, фигуру можно назвать призмой сработки грунтовых вод. Площадь сечения этой призмы может быть математически выражена как двойной интеграл функций, аппроксимирующих кривые максимального и минимального положения УГВ. Совмеще-

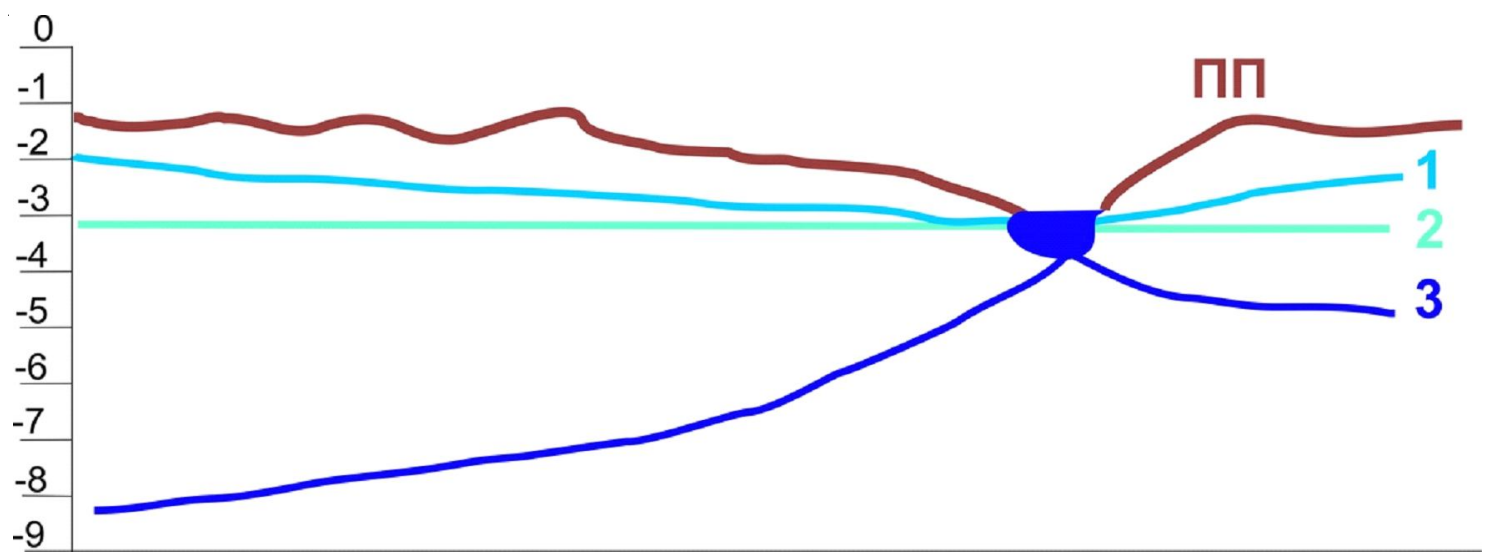

Рис. 1. Типы динамики грунтовых вод пойм в меженный период ПП - поверхность поймы:

1, 2, 3 - типы положения уровня грунтовых вод в меженный период (пояснения в тексте) 
ние нескольких профилей УГВ для одного тестового участка и интерполяция в геоинформационной среде позволит получить поверхности грунтовых вод в период половодья и межени, вычисление объема призмы сработки грунтовых вод возможно вычитанием этих поверхностей. Такой подход позволяет формализовать результаты наблюдений, использовать математические инструменты их обработки и получать объективные численные значения.

Основная идея исследования - определение границ географического распространения 3-х типов динамики грунтовых вод, выявление их связи с почвами и растительностью пойм. Отдельной проблемой является разработка четких количественных критериев интразональности, которые будут выявлены путем математической обработки данных по динамике грунтовых вод речных пойм, полученных в результате полевых исследований.

Традиционно ландшафты пойм изучают, увязывая их состояние с режимом поверхностных и грунтовых вод (ГВ). Глубину зеркала грунтовых вод при этом обычно определяют, ввиду трудоемкости, по 1-2 скважинам на профиле. Данные об уровне грунтовых вод (УГВ) в небольшом количестве скважин служат основой для построения полиноминальных трендов. При этом обычно не учитывается состав грунтов, который существенно влияет на положение зеркала ГВ. Мы используем для определения УГВ данные геофизического (геора- дарного) профилирования, которые позволяют получить отметки УГВ по всей линии профиля. В качестве рабочих приборов используются георадар ОКО-2 с антенными блоками 150/ 400 МГц и АБДЛ «Тритон», которые имеют максимальные в семействе георадаров ОКО глубины сканирования и позволяют определять достоверные отметки УГВ на любых поймах, а также состав и стратиграфию грунтов по линии профиля. Поскольку профили фиксированы в системе географических координат, то каждая точка поверхности зеркала грунтовых вод получает точную пространственную привязку, что позволяет оцифровывать результаты и обрабатывать их, используя чертежное или картографическое программное обеспечение.

Алгоритм работ выглядит следующим образом:

1. Выбор ключевых участков исследования, геодезическое профилирование этих участков, увязка с уровнем поверхностных вод.

2. Определение глубины залегания зеркала грунтовых вод геофизическими методами в разные периоды года.

3. Контроль результатов путем наблюдения в скважинах и колодцах (в том числе и с применением дистанционных самописцев-логгеров).

4. Картографирование результатов и расчет объемов и расходов грунтовых вод по сезонам, построение 3D-моделей динамики грунтовых вод.

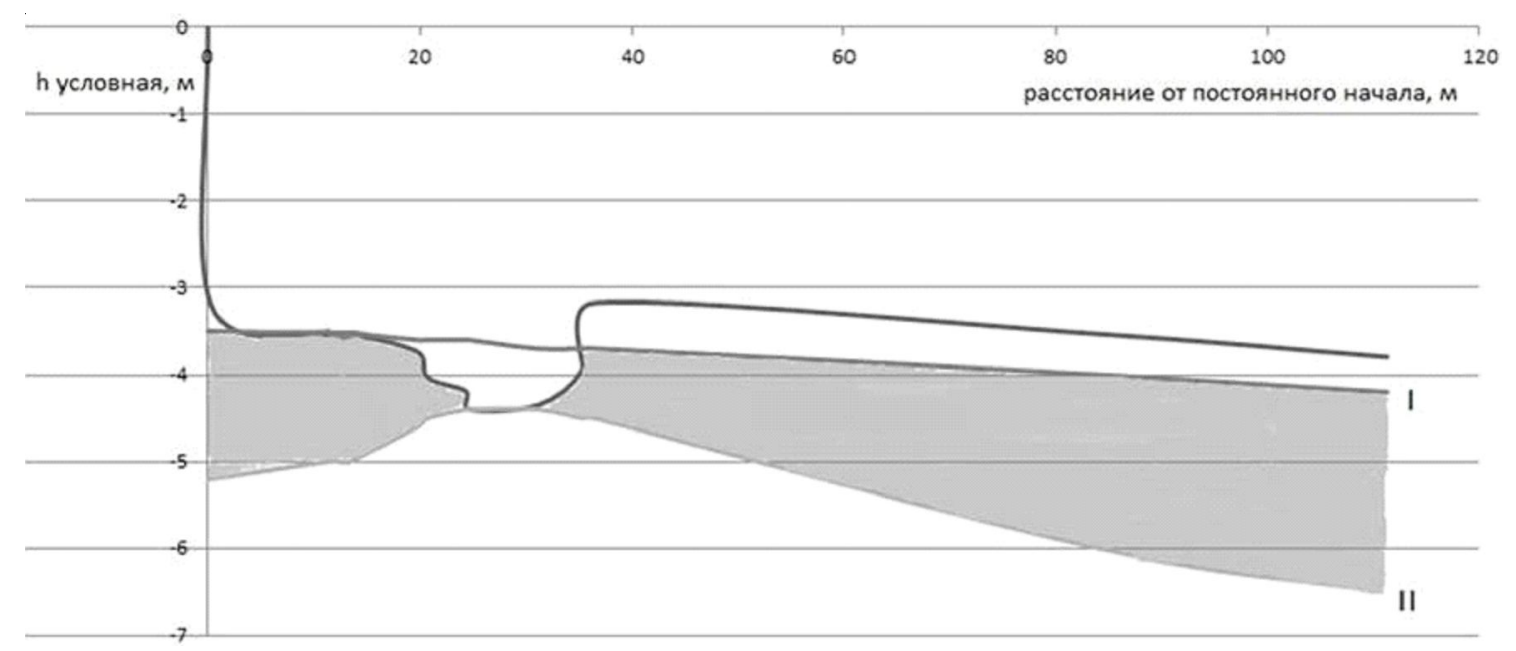

Рис. 2. Совмещенный профиль рельефа положения зеркала грунтовых вод:

I - положение зеркала грунтовых вод в период половодья;

II - положение зеркала грунтовых вод в меженный период 
5. На полевом этапе работ описываются также почвы и растительные сообщества по линии профиля, определяются спектрорадиометрические характеристики поверхности.

Полевой спектрорадиометр PSR1100, имеющийся в распоряжении коллектива, позволяет определять особенности спектра отраженного растениями излучения. Растительные сообщества являются индикаторами почвенных условий, глубины залегания и минерализации грунтовых вод. База данных спектров различных фитоценозов и почв в совокупности с данными о глубинах залегания грунтовых вод позволит проводить дифференциацию ландшафтов на основе дешифрирования спектрозональных космических снимков. Анализ спектров излучения отдельных растений позволит изучить реакцию различных видов на изменение глубины залегания грунтовых вод. Это, в свою очередь, позволяет распространить данные с ключевых участков наблюдений на всю площадь пойм рек района исследований.

Главным результатом исследованийдолжна стать типология (классификация) ландшафтов речных пойм южной части Русской равнины, основанная на объективных количественных показателях. Она выведет описательные исследования ландшафтов речных пойм, которые пока абсолютно преобладают в научной литературе, на новый уровень. В прикладном плане типология станет основой природопользования и оценки экологических рисков для пойменных ландшафтов (лесное хозяйство и промышленность, земледелие, оценка сенокосов и пастбищ, подземные источники водоснабжения для населенных пунктов, рекреационное природопользование и пр.).

\section{ПРИМЕЧАНИЕ}

${ }^{1}$ Работа выполнена при финансовой поддержке Российского фонда фундаментальных исследований и Администрации Волгоградской области в рамках научного проекта № 18-45-342004.

\section{СПИСОК ЛИТЕРАТУРЫ}

1. Анучина, Н.А. Характеристика деятельности коллективных средств размещения Волгоградской области в период 2010-2015 гг./ Н.А. Анучина,
О.Ю. Зеленская, Д.А. Семенова // Антропогенная трансформация геопространства: история и современность. Материалы IV Международной научнопрактической конференции. - Волгоград: Изд-во ВолГУ, 2017. - С. 61-66.

2. Болгов, М.В. Водно-экологические проблемы Волго-Ахтубинской поймы / М.В. Болгов, К.Ю. Шаталова, О.В. Горелиц, И.В. Землянов // Экосистемы: экология и динамика. - 2017. Том 1. - № 3. - С. 15-37.

3. Вишняков, Н.В. Современное состояние, гидрологическая характеристика и пути оптимизации использования водных объектов бассейна реки Большая Голубая/ Н.В. Вишняков, С.Н. Канищев, Д.А. Солодовников // Вестник Волгоградского государственного университета. Серия 3. Экономика. Экология. - 2015. - № 4. - С. 268-277.

4. Валов, М.В. Влияние первичных и вторичных экологических факторов на динамику почвенно-растительного покрова долгопойменных территорий интразональных дельтовых ландшафтов реки Волги/ М.В. Валов, А.Н. Бармин, А.Ю. Колотухин, Е.А. Бармина // Геология, география и глобальная энергия. 2017. - № 2 (65). - С. 93-104.

5. Карабаева, А.З. Характеристика морфологической структуры урочищ интразонального ландшафта центральной части дельты Волги / А.З. Карабаева, И.В. Быстрова, В.В. Занозин, О.Г. Карабаева / / Естественные науки. - 2012. - № 3 (40). - С. 55-59.

6. Кузьмина, Ж.В. Динамические изменения наземных экосистем поймы и дельты Нижней Волги под влиянием зарегулирования речного стока и климатических флуктуаций/Ж.В. Кузьмина, С.Е. Трешкин, Т.Ю. Каримова // Аридные экосистемы. 2015. - № 4 (65). - С. 39-53.

7. Кузьмина, Ж.В. Влияние зарегулирования речного стока и изменений климата на динамику наземных экосистем Нижней Волги / Ж.В. Кузьмина, С.Е. Трешкин, С.С. Шинкаренко // Аридные экосистемы. - 2018. - Том 24. - № 4 (77). - С. 3-18.

8. Бармин, А.Н. Особенности каузального характера связей гидрологического режима и динамики растительных сообществ интразональных ландшафтов аридных территорий (на примере лугов среднего уровня дельты реки Волги) / А.Н. Бармин, М.В. Валов, М.М. Иолин, Е.А. Бармина, И.М. Куренцов // Научные ведомости Белгородского государственного университета. Серия: Естественные науки. - 2016. - Т. 34. - № 4 (225). - С. 39-47.

9. Паракшин, Ю.П. О зональности интразональных почв / Ю.П. Паракшин, Э.М. Паракшина / / Вестник Балтийского федерального университета им. И. Канта. Серия: Естественные и медицинские науки. - 2013. - № 7. - С. 127-135.

10. Пилипенко, В.Н. Экологические последствия влияния зарегулирования стока реки Волги 
на флору, растительность и почвенный покров дельты Волги / В.Н. Пилипенко, А.В. Федотова, С.Н. Перевалов, В.А. Сагалаев // Вестник Оренбургского государственного университета. - 2006. - № 2-2 (52). - C. 22-29.

11. Полубаринова-Кочина, П.Я. Теория движения грунтовых вод./ П.Я. Полубаринова-Кочина М.: Наука, 1977. - 664 с.

12. Попов, И.В. Деформации речных русел и гидротехническое строительство/ И.В. Попов - Л.: Гидрометеоиздат, 1965. - 328 с.

13. Природа и сельское хозяйство Волго-Ахтубинской долины и дельты Волги. - М.: МГУ, 1962. $-452 \mathrm{c}$.

14. Солодовников, Д.А. Формы рекреационного природопользования на территории Волго-Ахтубинской поймы / Д.А.Солодовников, С.Н. Канищев, Д.В. Золотарев, С.С. Шинкаренко // Вестник Волгоградского государственного университета. Серия 11: Естественные науки. - 2013. - № 2 (6). - С. 53-61.

15. Сурков, В.В. Ярусность природных территориальных комплексов в речных поймах как функция русловых и гидрологических процессов/ В.В. Сурков // Вестник Томского государственного университета. -2013. - №372. - С. 197-202.

16. Филиппов, О.В. Пятидесятилетние итоги развития берегов Волгоградского водохранилища / О.В. Филиппов, Д.А. Солодовников // Стрежень: Научный ежегодник. - 2010. - № 8. - С. 135-139.

17. Филиппов, О.В. Опыт восстановления деградированных ландшафтов и водных объектов Волго-Ахтубинской поймы: гидрологический аспект / О.В. Филиппов, Д.А. Солодовников, Д.В. Золотарев, С.Н. Канищев // Вестник Волгоградского государственного университета. Серия 11. Естественные науки. - 2012. - № 2 (4). - С. 34-43.

18. Шеппель, П.А. Паводок и пойма. / П.А. Шеппель-Волгоград, 1986. - 239 с.

19. Белоусова, А.П. Экологическая гидрогеология. / А.П. Белоусова, И.К. Гавич, А.Б. Лисенков, Е.В. Попов - М.: Академкнига, 2006. - 400 с.

20. Валов, М.В. Экотонныегеосистемы дельты р. Волги: структурно-динамические особенности функционирования почвенно-растительного покрова/ М.В. Валов, А.Н. Бармин, Е.А. Бармина, О.С. Ерошкина, Е.Е. Жаднов // Современные проблемы территориального развития. - 2017. - № 3. [Электронный pecypc https://terjournal.ru/wpcontent/uploads/2017/10/ID17.pdf / (дата обращения 04.12.2018)].

21. Ямнова, И.А. Засоление почв дельты р. Волга и района западных ильменей / И.А. Ямнова, Г.И. Черноусенко, Н.И. Сотнева // Бюллетень Почвенного института им. В.В. Докучаева. - 2005. - С. 31-42.

22. Batelaan, O. Regional groundwater discharge: phreatophyte mapping, groundwater modelling and impact analysis of land-use change / O. Batelaan, F. De Smedt, L. Triest //Journal of Hydrology. - 2003. T. 275. - № 1-2. - P. 86-108.

23. Freeze, R.A. Groundwater / R.A. Freeze, J.A. Cherry-Englewood Cliffs: Prentice-Hall, 1979. $604 \mathrm{p}$.

24. Selroos, J.O. Comparison of alternative modelling approaches for groundwater flow in fractured rock/ J.O. Selroos, D.D. Walker, A. Strom, B. Gylling, S. Follin //Journal of Hydrology. - 2002.T. 257. - № 1-4. - P. 174-188.

25. Stuyfzand, P.J. Patterns in groundwater chemistry resulting from groundwater flow/ P.J. Stuyfzand //Hydrogeology Journal. - 1999. T. 7. - №1. - P. 15-27.

26. Tharme, R. A global perspective on environmental flow assessment: emerging trends in the development and application of environmental flow methodologies for rivers/ R. Tharme // River research and applications. - 2003. - V. 19. - Issue 5-6. - P. 397-441.

\section{REFERENCES}

1. Anuchina N.A., Zelenskaja O.Ju., Semenova D.A. Harakteristika dejatel'nosti kollektivnyh sredstv razmeshhenijaVolgogradskoj oblasti v period 2010-2015 gg. [Characteristics of collective means of accommodation of the Volgograd region in the period 2010-2015].//Antropogennaja transformacija geoprostranstva: istorija i sovremennost'. Materialy IV Mezhdunarodnoj nauchno-prakticheskoj konferencii [Anthropogenic transformation of geospatial space: history and modernity. Proceedings of the IV International scientific-practical conference]. Volgograd: IzdvoVolGU, 2017. pp. 61-66.

2. Bolgov M.V., ShatalovaK.Ju., Gorelic O.V., Zemljanov I.V. Vodno-jekologicheskie problemyVolgoAhtubinskojpojmy [Water-ecological problems of the Volga-Akhtuba floodplain].Jekosistemy: jekologija i dinamika [Ecosystems: ecology and dynamics]. 2017. Vol. 1. № 3. pp. 15-37.

3. Vishnjakov N.V., Kanishhev S.N., Solodovnikov D.A. Sovremennoe sostojanie, gidrologicheskaja harakteristika i puti optimizacii ispol'zovanija vodnyh ob\#ektov bassejna reki Bol'shaja Golubaja [Current status, hydrological characteristics and ways to optimize the use of water bodies of the BolshayaGolubaya river basin]. Vestnik Volgogradskogo gosudarstvennogo universiteta. Serija 3: Jekonomika. Jekologija.[Bulletin of Volgograd state University. Series 3: Economy. Ecology.]. 2015. №4. pp. 268-277.

4. Valov M.V., Barmin A.N., KolotuhinA.Ju., Barmina E.A. Vlijanie pervichnyh i vtorichnyh 
jekologicheskih faktorov na dinamiku pochvennorastitel'nogo pokrova dolgopojmennyh territory jintrazonal'nyh del'tovyh landshaftov reki Volgi [Influence of primary and secondary environmental factors on the dynamics of soil and vegetation cover of long-term territories of the intrazonal Delta landscapes of the Volga river]. Geologija, geografija i global'naja jenergija [Geology, geography and global energy]. 2017. № 2 (65). pp. 93-104.

5. Karabaeva A.Z., Bystrova I.V., Zanozin V.V., Karabaeva O.G. Harakteristika morfologicheskoj struktury urochish intrazonal'nogo landshafta central'noj chaste del'tyVolgi [Characteristics of the morphological structure of the tracts of the intrazonal landscape of the Central part of the Volga Delta]. Estestvennyenauki [Natural science].2012. № 3 (40). pp. 55-59.

6. Kuz'minaZh.V.,Treshkin S.E., KarimovaT.Ju. Dinamicheskie izmenenija nazemnyh jekosistem pojmyi del'tyNizhnejVolgi pod vlijaniem zaregulirovanija rechnogo stoka i klimaticheskih fluktuacij [Dynamic changes in terrestrial ecosystems of the floodplain and lower Volga Delta under the influence of river flow regulation and climatic fluctuations]. Aridnyej ekosistemy [Arid ecosystems].2015. № 4 (65). pp. 39-53.

7. Kuz'mina Zh.V., Treshkin S.E., Shinkarenko S.S. Vlijanie zaregulirovanija rechnogo stoka i izmenenij klimatanadinamiku nazemnyh jekosistem Nizhnej Volgi [Influence of river flow regulation and climate change on the dynamics of terrestrial ecosystems of the Lower Volga]. Aridnyej ekosistemy [Arid ecosystems]. 2018. Vol. 24. № 4 (77). pp. 3-18.

8. Barmin A.N., Valov M.V., Iolin M.M., Barmina E.A., Kurencov I.M. Osobennosti kauzal'nogo haraktera svjazej gidrologicheskogo rezhima i dinamiki rastitel'nyh soobshhest v intrazonal'nyh landshaftov aridnyh territorij (na primere lugov srednego urovnja del'ty reki Volgi) [Features of the causal nature of the links in the hydrological regime and dynamics of plant communities in the intrazonal landscapes of arid areas (for example, meadows the average level of the Delta of the Volga river)]. Nauchnye vedomosti Belgorodskogo gosudarstvennogo universiteta.Serija: Estestvennye nauki [Scientific sheets of the Belgorod state University. Series: Natural Sciences.]. 2016. Vol. 34. № 4 (225). pp. 39-47.

9. ParakshinJu.P., ParakshinaJe.M. O zonal'nosti intrazonal'nyh pochv [On zoning of intrazonal soils]. Vestnik Baltijskogo federal'nogo universiteta im. I. Kanta. Serija: Estestvennye i medicinskie nauki [Bulletin of the Baltic Federal University. I. Kant. Series: Natural and Medical Sciences]. 2013. № 7. pp. 127-135.

10. Pilipenko V.N., Fedotova A.V., Perevalov S.N., Sagalaev V.A. Jekologicheskie posledstvija vlijanija zaregulirovanija stoka reki Volgi na floru, rastitel'nost' i pochvennyj pokrov del'ty Volgi [Ecological consequences of the influence of the Volga river flow regulation on the flora, vegetation and soil cover of the Volga Delta]. Vestnik Orenburgskogo gosudarstvennogo universiteta [Bulletin of Orenburg State University]. 2006. № 2-2 (52). pp. 22-29.

11. Polubarinova-Kochina P.Ja. Teorija dvizhenija gruntovyh vod [Theory of groundwater movement]. Moscow: Nauka. 1977. 664 p.

12. Popov I.V. Deformacii rechnyh rusel i gidrotehnicheskoe stroitel'stvo [Deformations of river beds and hydraulic engineering]. Leningrad: Gidrometeoizdat, $1965.328 \mathrm{p}$.

13. Priroda i sel'skoehozjajstvoVolgoAhtubinskoj doliny i del'tyVolgi [Nature and agriculture of the Volga-Akhtuba valley and the Volga Delta]. Moscow: Moscow State University. 1962. 452 p.

14. Solodovnikov D.A., Kanishhev S.N., Zolotarev D.V., Shinkarenko S.S. Formy rekreacionnogo prirodopol'zovanija na territorii Volgo-Ahtubinskoj pojmy [Forms of recreational nature management on the territory of the Volga-Akhtuba floodplain]. Vestnik Volgogradskogo gosudarstvennogo universiteta. Serija 11: Estestvennye nauki [Bulletin of Volgograd State University. Series 11: Natural Sciences]. 2013. № 2 (6). pp. 53-61.

15. Surkov V.V. Jarusnost' prirodnyh territorial'nyh kompleksov v rechnyh pojmah kak funkcija ruslovyh i gidrologicheskih processov [Tiering of natural territorial complexes in river floodplains as a function of channel and hydrological processes]. Vestnik Tomskogo gosudarstvennogo universiteta [Bulletin of Tomsk State University].2013. № 372. pp. 197-202.

16. Filippov O.V., Solodovnikov D.A. Pjatidesjatiletnie itogi razvitija beregov Volgogradskogo vodohranilishha [Fifty-year results of the development of the banks of the Volgograd reservoir]. Strezhen': Nauchnyj ezhegodnik [Midstream: Scientific Yearbook]. 2010. № 8. pp. 135-139.

17. Filippov O.V., Solodovnikov D.A., Zolotarev D.V., Kanishhev S.N. Opyt vosstanovlenija degradirovannyh landshaftov i vodnyh objektov VolgoAhtubinskoj pojmy: gidrologicheskij aspekt [Experience of restoration of degraded landscapes and water bodies of the Volga-Akhtuba floodplain: hydrological aspect]. Vestnik Volgogradskogo gosudarstvennogo universiteta. Serija 11: Estestvennye nauki [Bulletin of Volgograd State University. Series 11: Natural Sciences]. 2012. № 2 (4). pp. 34-43.

18. Sheppel' P.A. Pavodok i pojma [Flood and floodplain]. Volgograd, 1986.239 p.

19. Belousova A. P., Gavich I. K., Lisenkov A. B., Popov E. V. Jekologicheskaja gidrogeologija [Environmental hydrogeology]. Moscow: Akademkniga, 2006. 400 p. 
20. Valov M.V., Barmin A.N., Barmina E.A., Eroshkina O.S., Zhadnov E.E. Jekotonnye geosistemy del'ty r. Volgi: strukturno-dinamicheskie osobennosti funkcionirovanija pochvenno-rastitel'nogo pokrova [Ecotonic geosystems of the Volga river Delta: structural and dynamic features of soil and vegetation cover functioning]. Sovremennye problem territorial'nogo razvitija [Modern problems of territorial development]. 2017. № 3. [Electronic resource https:// terjournal.ru/wp-content/uploads/2017/10/ID17.pdf/ (Date of appeal 04.12.2018)].

21. Jamnova I.A., Chernousenko G.I., Sotneva N.I. Zasolenie pochv del'ty r. Volga i rajona zapadnyh il'menej [Salinization of soils of the Volga Delta and Western Ilmen area]. Bjulleten' Pochvennogo institute im. V.V. Dokuchaeva [Bulletin of V. V. Dokuchaev's Soil Institute]. Moscow. 2005. pp. 31-42.

22. Batelaan O., De Smedt F., Triest L. Regional groundwater discharge: phreatophyte mapping, groundwater modelling and impact analysis of landuse change. Journal of Hydrology. 2003. T. 275. № 12.pp. 86-108.

23. Freeze R.A., Cherry J.A. Groundwater. Englewood Cliffs: Prentice-Hall, 1979. 604 p.

24. Selroos J.O., Walker D.D., Strom A., Gylling B., Follin S. Comparison of alternative modelling approaches for groundwater flow in fractured rock. Journal of Hydrology. 2002. T. 257. № 1-4.pp. 174-188.

25. Stuyfzand P.J. Patterns in groundwater chemistry resulting from groundwater flow. Hydrogeology Journal. 1999. T. 7. № 1. pp. 15-27.

26. Tharme R. A global perspective on environmental flow assessment: emerging trends in the development and application of environmental flow methodologies for rivers // River research and applications. 2003. V. 19. Issue 5-6. pp. 397-441.

\section{Information about the Author}

Denis A. Solodovnikov, Candidate of Geographical Sciences, Associate Professor, Head of Department of Geography and Cartography, Volgograd State University, Prosp. Universitetsky, 100, 400062 Volgograd, Russian Federation, densolodovnikov@gmail.com, solodovnikov@volsu.ru.

\section{Информация об авторе}

Денис Анатольевич Солодовников, кандидат географических наук, доцент, заведующий кафедрой географии и картографии, Волгоградский государственный университет, просп. Университетский, 100, 400062 г. Волгоград, Российская Федерация, densolodovnikov@gmail.com, solodovnikov@volsu.ru. 